\title{
An Epidemiological Study of Measles Incidence and Vaccination Coverage in Urban Slums of Ahmedabad, India
}

\author{
Rajendra N. Gadhavi ${ }^{1}$, Himanshu Nayak ${ }^{2}$, Jakasania Arjunkumar ${ }^{1}$, Ashwin Kumar Modi ${ }^{3}$
}

\section{Rajendra N. Gadhavi ${ }^{1}$, Himanshu Nayak ${ }^{2}$, Jakasania Arjunkumar ${ }^{1 *}$, Ashwin Kumar Modi ${ }^{3}$}

${ }^{1}$ Department of Community Medicine, B.J. Medical College, Ahmedabad, Gujarat, INDIA.

2Department of Community Medicine, L.G Medical College, Ahmedabad, Gujarat, INDIA.

${ }^{3}$ Post Doctoral Fellow, Medical Science Campus, University of Puerto Rico, PR, USA.

\section{Correspondence}

Dr. Jakasania Arjunkumar

B/ 49 Yash Bungalows,

Opp. Jagdishnagar Society, Ghodasar,

Ahmedabad, Gujarat, INDIA.

Mobile no: 9510881542

Email: aarrjjuunn999@gmail.com

\section{History}

- Submission Date: 18-01-2018

- Revised Date: 11-05-2018

- Accepted Date: 24-06-2018

DOI : 10.5530/ijmedph.2018.2.13

\section{Article Available online}

http://www.ijmedph.org/v8/i2

\section{Copyright}

(C) 2018 Phcog.Net. This is an openaccess article distributed under the terms of the Creative Commons Attribution 4.0 International license.

\begin{abstract}
Background: Measles is the public health problem in India, causing mortality and morbidity in children. Measles vaccination is included in the Immunization program but low coverage is still a major problem. There is a lack of data on measles incidence and coverage in vulnerable population for measles. Methodology: A cross-sectional study was carried out to find out the incidence and vaccination coverage based on parents recall in identified 30 slums of Ahmedabad by using cluster sampling method. 3000 children, less than five years of age were included by selecting 100 children from each cluster. Pre-designed and pre-tested standardized questionnaire of UNICEF was used to assess symptoms of measles and history of the Immunization. Result: The measles incidence was found $20.8 \%$ based on symptoms and $3.03 \%$ based on confirmed diagnosis by doctors as per parents recall in the past six months. The overall vaccination coverage was found at $64.62 \%$. The most common presenting symptom was found fever with rash in children with measles. Conclusion: No gender difference was found in vaccine coverage, measles incidence and status of treatment received. Vaccine efficacy found to be $42 \%$ which is very low and high incidence of measles was reported which shows the need for an effective targeted program for the urban slums.

Key words: Immunization, Measles, Symptoms, Vaccine efficacy, Cluster, Ahmedabad.
\end{abstract}

\section{INTRODUCTION}

Measles is an infectious disease caused by Morbillivirus, ${ }^{1}$ which usually affects children with more than $80 \%$ secondary attack rate. However, multiple outbreaks of the disease have even been reported among adults in urban slums, disaster relief camps, during international travel, etc. ${ }^{2-5}$ The disease is characterised by the presence of fever, cough, and coryza, followed by the appearance of a typical rash. ${ }^{1}$ The disease is transmitted by the airborne route. Being a viral disease large proportions of cases are self-limiting, still, multiple deaths have been reported because of disease-associated complications. ${ }^{6}$ In developing countries like India, more than 2 million children die of measles every year. Live attenuated measles vaccination is an effective means of reducing the incidence of measles in many countries and presently the age of immunisation with measles vaccine is nine months with two doses of measles vaccination have been suggested as a strategy to control measles. Measles vaccination was introduced in India under the universal immunisation (UIP) during 1985-86. Vaccination coverage increased to $87 \%$ in 1994-95 resulting in a decline in measles incidence from 160216 cases in 1985 to 61381 cases in $1996 .^{7}$ In spite of extensive immunisation coverage under the universal immunisationprogram (UIP) in Gujarat, measles still remains a major cause of childhood morbidity and mortality. Gujarat is one of the industrialised states of India. Ahmedabad is the biggest city in Gujarat. Urbanisation has led to migration from a rural area which resulted in the growth of urban slums. Overcrowding, lack of hygiene and sanitation facilities may lead to spread of infectious diseases like measles. Lack of awareness and health seeking behaviour further leads to low vaccine coverage of measles thus children living in urban slums are vulnerable to measles. Poor treatment seeking behaviour due to cultural beliefs leads to higher chances of complications of measles and might be resulted in death. There is a paucity of measles incidence and vaccination coverage data due to non-reporting of the cases. ${ }^{8-9}$ For effective immunisation programme, it's implementation and monitoring baseline data are required and with this background the present study was conducted to assess the incidence of measles and vaccination coverage in the slums of Ahmedabad city.

\section{MATERIALS AND METHODS}

A community-based cross-sectional study was carried out adopting cluster sampling method. A sample size was calculated by expecting coverage of about $70 \%$ vaccination ${ }^{10}$ for children less than 5 years of age and expecting all the unvaccinated children to have got an attack of measles by the age of five years uniformly through the five years. Thus, $6 \%$ cases of measles in the study population per year assumed with an relative precision of 25 percent and design effect of 3 at 95 percent significance level (alpha risk of
Cite this article : Gadhavi RN, Nayak H, Jakasania AH, Modi AK. An Epidemiological Study of Measles Incidence and Vaccination Coverage in Urban Slums of Ahmedabad, India. Int J Med Public Health. 2018;8(2):58-61. 
5 percent), the required sample size was calculated as 2888 , by using formula manually, $\mathrm{N}=\mathrm{Z}(\alpha / 2)^{2} \mathrm{p}(1-\mathrm{p}) / \mathrm{D}^{2}$ [Where $\mathrm{p}$ is prevalence and $\mathrm{D}$ is relative precision $(Z=1.96)] .{ }^{11}$ So, 3000 children were included in this study. Total 30 wards out of 64 wards in Ahmedabad city were selected by cluster sampling method according to population proportionate to sample size technique; each of the selected clusters was divided into four quadrants. From each quadrant's total households a random number was selected and the houses were studied beginning from that number till a total number of 25 children in that quadrant between the age of 9-59 months, giving a total of 100 children in each cluster. A predesigned and pretested standardised Performa used for measles incidence study by $\mathrm{UNICEF}^{12}$ and recommended for the baseline incidence study was used after pretesting and necessary modifications as per local requirements. Measles was suspected when the mother had given a history of the measles for her child in last six months. It was further confirmed by inquiring the presence of symptoms:

1. History of fever more than 38 degree Celsius or 'hot to touch'

2. Rash for 3 days or more

3. Cough and cold/URTI

4. Conjunctivitis or redness of eyes

5. Distribution of the rash which is from the face down to the body

6. Blackish Discoloration of the skin after the rash disappeared.

For, the measles incidence, mother's history was considered as reliable. However, to what extent the other confirmatory symptoms tally with the mother/relative's history was also documented. We also inquired whether the diagnosis was confirmed or not by the doctor. The relevant information regarding measles vaccination and vitamin A status was also obtained and documented.

\section{Data Collection}

The project coordinator had held a training session for the intern doctors and investigators who were going to be involved in the data collection and supervision respectively. A team composed of two field investigators will collect the data under the close supervision of project coordinators and investigators.

\section{Data Analysis}

Data collected and compiled into Microsoft excel and data entry was dually checked to prevent any error. Both qualitative and quantitative variables were analysed with the help of Epi-info 7 software and significance was tested.

\section{RESULT}

Table 1 is showing that, out of 3000 children, 1715 (57.2\%) were boys while $1285(42.8 \%$ ) were girls. Mean age of boys and girls was $29.99 \pm 14.21$ and $29.52 \pm 14.20$ respectively and the difference wasn't found statistically significant $(\mathrm{Z}=0.89, \mathrm{P}>0.05)$.

Table 2 is showing an association of sex with measles vaccination status and measles disease. There is no statistically significant association found between sex of child and measles disease, vaccination status and treatment of measles as per chi-square test. $(p>0.05)$

Table 3 displays measles cases as per the history given by the parents regarding measles in past six months. It explains very high incidence (20.8\%) of measles in the urban slums of Ahmedabad city. It shows a high incidence of measles among $12-23$ months age (29.6\%) followed by 24-35 months (28.7\%) while lower incidence (9.3\%) during the first year of life. Out of 624 cases, only 91 cases were confirmed the diagnosis of measles by the doctors. If we consider this than the incidence of measles is 3.03. Highest proportion (34.0\%) of cases was from 12-23 months of

\begin{tabular}{|c|c|c|c|c|}
\hline \multirow{2}{*}{$\begin{array}{c}\text { Sr. No. } \\
1\end{array}$} & \multicolumn{2}{|c|}{ Variable } & \multirow{2}{*}{$\begin{array}{c}\mathrm{N}=3000 \\
1285\end{array}$} & \multirow{2}{*}{$\begin{array}{c}\% \\
42.8\end{array}$} \\
\hline & Sex & Male & & \\
\hline & & Female & 1715 & 57.2 \\
\hline \multirow[t]{5}{*}{2} & Age & $9-11$ & 367 & 12.2 \\
\hline & In months & $12-23$ & 937 & 31.2 \\
\hline & & $24-35$ & 735 & 24.5 \\
\hline & & $36-47$ & 623 & 20.8 \\
\hline & & $48-59$ & 338 & 11.3 \\
\hline \multirow[t]{3}{*}{3} & Religion & Christian & 4 & 0.1 \\
\hline & & Hindu & 2903 & 96.8 \\
\hline & & Muslim & 93 & 3.1 \\
\hline \multirow[t]{2}{*}{4} & Type of family & Joint & 1399 & 46.6 \\
\hline & & Nuclear & 1601 & 53.4 \\
\hline \multirow[t]{2}{*}{5} & SEC & Low & 2387 & 79.6 \\
\hline & & Middle & 613 & 20.4 \\
\hline
\end{tabular}

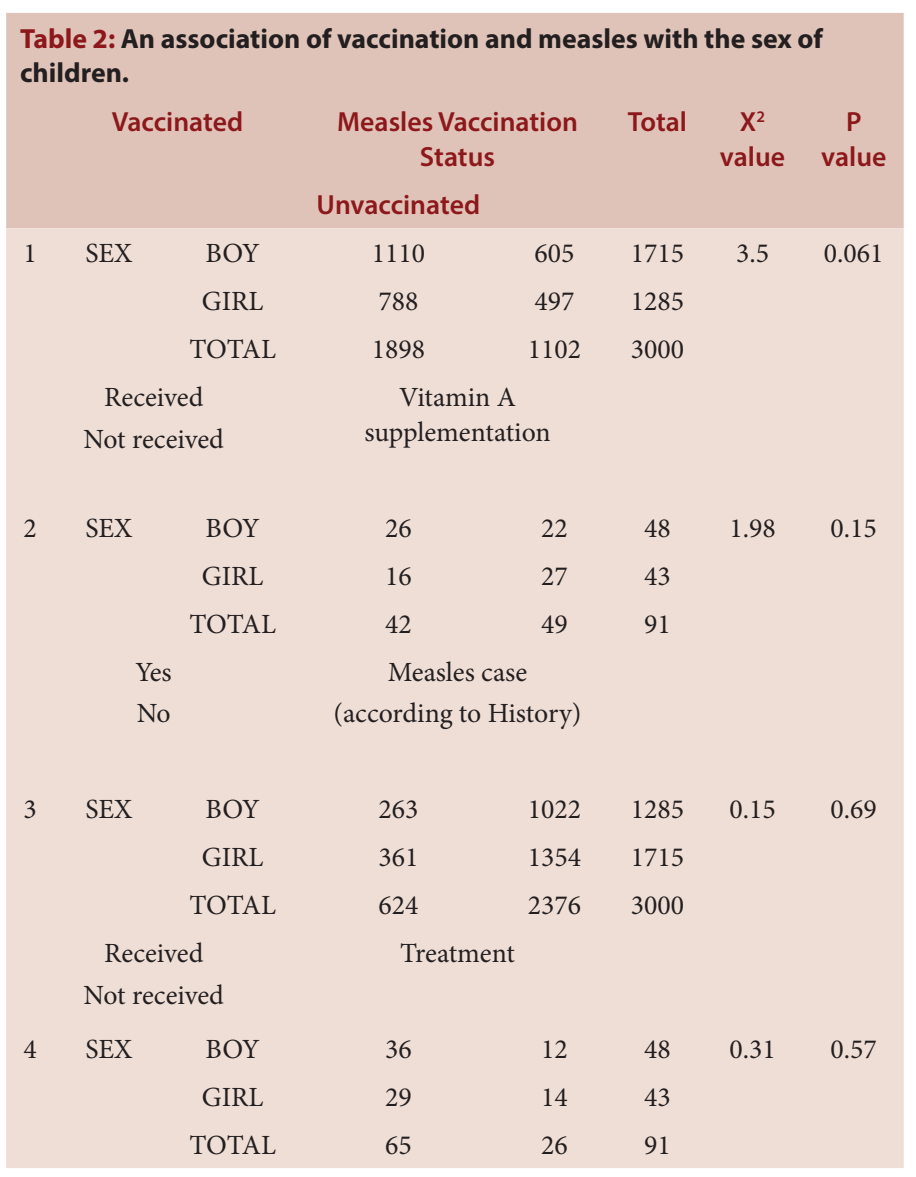

age while lowest (8.8\%) cases were from 9-11 months of age. There was no statistically significant association was found between age and measles occurrence $\left(\mathrm{x}^{2}=2.98, p=0.56\right)$.

Table 4 is showing coverage rate of measles vaccine among boys and girls in different age groups. 48-59 months age group children having highest vaccine coverage rate, following age group of 36-47 months children. 
Rajendra, et al .: Measles Vaccination Coverage in Ahmedabad.

\begin{tabular}{|c|c|c|c|c|c|}
\hline Age(Months) & Diagnosis as per History & Incidence rate (\%) & Diagnosis by Doctor & Incidence rate (\%) & Total \\
\hline $9-11$ & 58 & 9.3 & 8 & 2.18 & 367 \\
\hline $12-23$ & 185 & 29.6 & 31 & 3.36 & 937 \\
\hline $24-35$ & 179 & 28.7 & 18 & 2.46 & 735 \\
\hline $36-47$ & 138 & 22.7 & 23 & 3.7 & 623 \\
\hline $48-59$ & 64 & 10.5 & 11 & 3.25 & 338 \\
\hline Total & 624 & 20.8 & 91 & 3.03 & 3000 \\
\hline
\end{tabular}

\begin{tabular}{|c|c|c|c|c|c|c|}
\hline \multirow[b]{2}{*}{ Age(Months) } & \multicolumn{2}{|c|}{ boys } & \multicolumn{2}{|c|}{ girls } & \multicolumn{2}{|c|}{ total } \\
\hline & Total children & Coverage rate (\%) & Total children & Coverage rate (\%) & Total children & Coverage rate (\%) \\
\hline $12-23$ & 455 & 43.8 & 482 & 45 & 937 & 44.4 \\
\hline 24-35 & 293 & 71.9 & 442 & 68.5 & 735 & 70.2 \\
\hline Total & 1285 & 65.282 & 1715 & 63.97 & 3000 & 64.624 \\
\hline
\end{tabular}

The majority (52.7\%) of patients had consulted government facility for the diagnosis and treatment of measles. Only 24 patients had given a history of hospitalisation because of measles but couldn't remember thereason for the hospitalisation.

The vaccine efficacy calculated from this study was $42 \%$, calculated by comparing attack rate among vaccinated and unvaccinated with following formula;

$$
\text { Vaccine efficacy }(\%)=\frac{\text { ARU }-A R Y}{A R U} * 100=(1-R R) \star 100
$$

$\mathrm{ARU}=$ attack rate among unvaccinated

$\mathrm{ARV}=$ attack rate among vaccinated

$$
\mathrm{RR}=\frac{\mathrm{ARV}}{\mathrm{ARU}}
$$

\section{DISCUSSION}

India is having a diverse population with different cultural beliefs and geographic locations. Education of parents, poverty, taboos related health and other factors severely affect the health of their children. Measles is still a public health problem in India even though intensive immunisation program. Measles is still contributing to child mortality and morbidity till now. Measles vaccination coverage rate is low than others vaccines. ${ }^{10}$ Thus, incidence of measles and death related to complications of measles are still not so uncommon in India, thus the Government of India has adopted strategies which include achieving high coverage with the first dose of the measles vaccine (i.e. first-dose coverage for the measles vaccine must be $>90 \%$ at the national level and $>80 \%$ for each district); intensive surveillance activities; appropriate case management (including administration of vitamin A); and implementation of catch-up measles vaccination campaigns for children aged 9 months to 10 years in states with $<80 \%$ evaluated coverage with the first dose of measles vaccine..$^{8-9}$ The Indian District Level Health Survey_3 reported that only 30\% of vaccinated infants received the measles vaccine at the recommended age of 9 months despite intensive measures taken by the Government. ${ }^{13}$

The present study has found incidence rate of measles by the history of the child based on symptoms presented at that time. The incidence rate was found $20.8 \%$. Out of them, 91 children have been diagnosed as a confirmed case of measles by doctors and thus 3.03\% children having confirmed measles disease. The incidence of measles in Ahmedabad was documented $11.20 \%$ in a study done by Bhagyalaxmi A et al. ${ }^{11}$ A Study conducted by Desai VK et al. in Surat has found an incidence rate of measles $7.67 \%$ in one year period in children of age less than five years. ${ }^{14}$ The incidence study conducted in 1999 in Ahmedabad has shown 11.4\% incidence of measles. ${ }^{15}$ The present study was conducted in urban slums which might be a cause of higher incidence rate of measles. Data has been collected by trained intern doctors assuring least chance of skipping any case, which might be one of the reasons of reported higher incidence. The study conducted by Dollimer $\mathrm{N}$ et al. has shown overall estimated measles incidence rate 24.3 per 1,000 child-years in rural Ghana. ${ }^{16}$

The vaccine coverage rate was found $64.624 \%$ in the present study in 9-59 age group and similar kind of study conducted in Ahmedabad by Bhagyalaxmi A et al. ${ }^{11}$ has shown $59.88 \%$ coverage rate of vaccination of measles. A coverage rate of measles vaccination in 12-23 age group children was found $44.4 \%$ and Desai VK et al. ${ }^{14}$ has documented $49.8 \%$ coverage rate of measles vaccination in children of 12-23 months in Surat city and $48.3 \%$ children of 9-59 months. A study conducted by Dollimer $\mathrm{N}$ et al. ${ }^{16}$ in rural Ghana has shown $48 \%$ coverage of measles vaccine. The incidence studies carried out in Ahmedabad, Rajkot and Jamnagar revealed overall vaccination coverage between 46.7 to $58.9 \%$ in 1999 . According to NFHS 3 data vaccine coverage in Gujarat state is documented $65.7 \%{ }^{10}$ and $65.2 \%$ according to DLHS-2 in Gujarat state. ${ }^{13}$ According to DLHS-2 report, vaccination coverage in the urban area is documented $76.8 \%$. The present study is showing low vaccination coverage might be because of recall bias due to retrospective nature of the study and high prevalence of illiteracy and less awareness regarding health services. Many vaccinations related taboos are also prevalent in urban slums which may also affect it. 
The vaccine efficacy is found $42 \%$ in the present study, which is low than documented efficacy of measles which is $85-90 \%{ }^{1,17}$ might be due to study is conducted in a slum area of Ahmedabad which is more vulnerable to disease transmission due to poor housing, sanitation facility and overcrowding. Vaccination status and occurrence of measles were based on parents recall which might be biased. And improper cold chain maintenance could be another reason of low vaccine efficacy. It has been calculated by finding risk ratio (attack rate in vaccinated/unvaccinated children). Measles vaccine efficacy was observed even lower which is $36 \%$ in a study conducted in Ahmedabad by Bhagyalaxmi A et al. ${ }^{11} \mathrm{~A}$ similar kind of study conducted by Desai VK et al. ${ }^{14}$ in Surat city has documented vaccine efficacy $55 \%$, which is showing a similar result with our study, as both studies have been conducted in urban slums.

Thus, to decrease morbidity and mortality of children due to measles effective targeted program should be framed for Urban slums which have different socio-demographic characteristics and poor environmental living condition. Effective immunisation could be possible by ensuring proper cold chain maintenance and $>90 \%$ coverage by the involving community in it. Targeted IEC efforts should be framed to increase awareness regarding measles and its vaccination. Reporting of measles cases and prompt treatment should be assured by effective surveillance of measles.

\section{Limitation of study}

The present study is carried out by asking history of children to the parents, thus it is retrospective in nature but an incidence study design should be prospective for a period of a year but it is resource and timeconsuming. In this study only past six months data were collected from the parents to minimise recall bias. This study has shown some important findings of immunisation coverage and measles incidence in the slum of Ahmedabad city which can be utilised for further control strategies.

\section{ACKNOWLEDGEMENT}

We are thankful to interns of our department to support us in the procedure of data collection and also acknowledge the co-operation of the parents for the study.

\section{CONFLICT OF INTEREST}

The authors declare no conflict of interest.

\section{ABBREVIATIONS}

UNICEF: United Nations Children's Fund; URTI: Upper respiratory tract Infection; DLHS: District Level Household Survey; NFHS: National Family Health Survey

\section{SUMMARY}

The present study was conducted to find out vaccination coverage and measles incidence in last 5 years as per parent's recall in urban slums of Ahmedabad by using cluster sampling method. The measles incidence was found $20.8 \%$ based on symptoms and $3.03 \%$ based on confirmed diagnosis by doctors as per parents recall in the past six months. The overall vaccination coverage was found at $64.62 \%$. No gender difference was found in vaccine coverage, measles incidence and status of treatment received. Vaccine efficacy found to be $42 \%$ which is very low and high incidence of measles was reported which shows the need for an effective targeted program for the urban slums.

\section{REFERENCES}

1. Park K. Epidemiology of communicable diseases. In: K Park (ed.), Textbook of preventive and social medicine, $21^{\text {st }}$ ed. Jabalpur, India: BanarsidasBhanot Publishers. 2011.

2. Patro BK, Shewade HD, Kathirvel S, Senjam SS, Singh MP, Ratho RK. Outbreak of "modified measles" in an urban resettlement colony of North India. Indian J Publ Health. 2012;56(2):168-9.

3. Arunkumar G, Vandana KE, Sathiakumar N. Prevalence of measles, mumps, rubella, and varicella susceptibility among health science students in a University in India. Am J Ind Med. 2013;56(1):58-64.

4. Mallik S, Mandal PK, Ghosh P, Manna N, Chatterjee C, Chakrabarty D, et al. Mass measles vaccination campaign in Aila cyclone-affected areas of West Bengal, India: an in-depth analysis and experiences. Iran J Med Sci. 2011;36(4):300-5.

5. Centres for Disease Control and Prevention (CDC). Notes from the field: measles outbreak associated with a traveller returning from India _ North Carolina, AprilMay 2013. MMWR Morb Mortal Wkly Rep. 2013;62(36):753.

6. Pan American Health Organization. Measles; 2015. Available from: http://www. paho.org/hq/index.php?option_com_topics\&view_article\&id_255\&ltemid_4089 9\&lang_en [cited 20 April 2017].

7. Ministry of Health and Family Welfare. Maternal and Child Health. Annual Report. 1996-97:25-32.

8. Vashishtha VM, Choudhury P, Bansal CP, Gupta SG. Measles control strategies in India: position paper of Indian Academy of Pediatrics. Indian Pediatr. 2013;50(6):561-4.

9. Nujum ZT, Varghese S. Investigation of an outbreak of measles: failure to vaccinate or vaccine failure in a community of predominantly fishermen in Kerala. J Infect Publ Health. 2015;8(1):11-9.

10. National family health survey (NFHS-3) 2005-2006 [Internet]. Mumbai: International Institute for Population Sciences (IIPS) and Macro International; 2009. Available from: http://www.rchiips.org/nfhs/nfhs4.shtml

11. Bhagyalaxmi A, Kedia G, Rawal V S, Study of incidence of measles and vaccination coverage in Ahmedabad urban slums. Indian journal of public health. 2007;51(1):52-3.

12. UNICEF, Multiple Indicator Survey. United Nations Children's Fund, 3 United Nations Plaza, New York, NY 10017, USA available at:- http://mics.unicef.org/tools.

13. District Level Household and Facility survey, International institute for population sciences, National Family Health Survey(3).

14. Vikas KD, Kapadia SJ, Pradeep K, Siddharth N. Study of measles incidence and vaccination coverage in slums of Surat city. Indian Journal of Community Medicine. 2003;28(1):10-4.

15. A compilation report on incidence studies of measles conducted in Ahmedabad, Baroda, Rajkot, Jamnagar and Surat.

16. Dollimore N, Cutts F et al. Measles incidence, case fatality and delayed mortality in children in rural Ghana. American Jornal of Epidemiology. 1997;146(8):646-54.

17. Measles Vaccine Efficacy in India: A Review J Singh et al. Journal of Communicable Diseases. 1997;29(1):47-56 